\title{
Effects of Annealing on the Microstructure and Wear Resistance of AlCoCrFeNiTio.5 High-entropy Alloy Coating Prepared by Laser Cladding
}

\author{
Sha Minghong, Zhang Li, Zhang Junwei, Li Na, Li Taizeng, Wang Ning \\ University of Science and Technology Liaoning, Anshan 114051, China
}

\begin{abstract}
Annealing behavior of $\mathrm{AlCoCrFeNiTi}_{0.5}$ high entropy alloy coatings prepared by laser cladding was investigated. The specimens were annealed at $900{ }^{\circ} \mathrm{C}$ for $5 \mathrm{~h}$. The microstructure and wear resistance of the as-annealed and as-cast specimens were investigated. The XRD results indicate that the as-annealed $\mathrm{AlCoCrFeNiTi} 0_{0.5}$ high entropy alloy coating is composed of $\mathrm{Al}_{80} \mathrm{Cr}_{13} \mathrm{Co}_{7}$, $\mathrm{Co}_{3} \mathrm{Ti}$, and AlFe solid solution phase. The SEM results and EDS data show that a typical spinodal decomposition structure with uniform composition is formed after annealing treatment. The average Vickers micro-hardness of the as-annealed coatings could reach $9890 \mathrm{MPa}$ which is increased by about $73.5 \%$ compared with that of the as-cast coatings. The abrasion resistance testing shows that the abrasion loss of the as-annealed coatings is reduced by $92.5 \%$ and the wear width is reduced by $50 \%$ compared with the values of as-cast coatings.
\end{abstract}

Key words: high-entropy alloy; annealing; wear resistance; laser cladding

High-entropy alloys (HEAs), which are defined as alloys containing at least five principal elements with atomic concentration between $5 \%$ and $35 \%$, have broken the traditional alloy design concept based on one or two principal components and emerged as a new research frontier in the metallic materials community ${ }^{[1]}$. According to recent study, the high entropy alloys have high lattice deformation and high mixing entropy so that the phases number of the frozen high entropy alloys is less than that forecasted by the equilibrium fraction. At the same time, high entropy alloys may form a simple fcc or bcc solid solution and nano-scale precipitation or amorphous. Therefore, high entropy alloys may possess high strength, high hardness, abrasion resistance, corrosion resistance, and oxidation resistance at high temperature ${ }^{[2,3]}$. Y. P. $\mathrm{Lu}^{[4]}$ and his research team had proposed a novel strategy to design HEAs using the eutectic alloy concept and successfully produced the bulk alloy ingot, which can be readily adapted to large-scale industrial production of HEAs with simultaneous high fracture strength and high ductility. Y. Dong et al ${ }^{[5,6]}$ investigated the effects of vanadium and Molybdenum element addition on the microstructure and mechanical properties of $\mathrm{AlCoCrFeNiV}_{x}$ and $\mathrm{AlCrFeNiMo}_{x}$ respectively. W. R. Wang ${ }^{[7]}$ et al have studied the $\mathrm{Al}_{x} \mathrm{CoCrFeNi}$ alloys with different aluminium contents. The result shows that with the increase of aluminium content, the phases in the alloys contain not only a simple fcc solid solution, but also bcc ones as main phases. Xiaoyan Luo ${ }^{[8]}$ et al have studied the hardness and the electrochemical characteristics of the AlFeCoNiCrTiV $\mathrm{A}_{0.5}$. The result shows that with the change of the annealing temperatures, alloy phases change and the phase transformation point is $900{ }^{\circ} \mathrm{C}$ during the annealing treatment of the alloy. Wei $\mathrm{Li}^{[9]}$ and his research team investigated the effects of Ti contents on the microstructure and properties of high entropy alloys; the microstructure is optimized, and the hardness reaches its maximum when Ti content is $x=0.5$ for $\mathrm{AlCoCrFeNiTi}_{x}$. Xiaoyan Luo ${ }^{[8]}$ and Y. F. Wang ${ }^{[10]}$ et al confirmed that the alloys had a good comprehensive mechanical property when annealing temperature was $900{ }^{\circ} \mathrm{C}$

Received date: May 06, 2016

Foundation item: National Natural Science Foundation of China ( 51201085); Science and Technology Plan Projects in Liaoning Province (2012415026); Innovation Research Team in University of Science and Technology Liaoning (2014TD02)

Corresponding author: Sha Minghong, Associate Professor, School of Materials and Metallurgy, University of Science and Technology Liaoning, Anshan 114051, P. R. China, E-mail: hongsmh_116@163.com 
and Ti content was $x=0.5$ for $\mathrm{AlCoCrFeNiTi}_{x}$ alloys. However, the studies of wear resistance are not reported for these alloys in recent years. Laser cladding is a rapidly developed surface treatment technique, which takes great advantages of rapid solidification velocity, fine microstructure, excellent metallurgical bonding, and little intermixing with the substrate. H. Zhang et $\mathrm{al}^{[11]}$ have prepared 6FeNiCoCrAlTiSi high-entropy alloy coating by laser cladding and investigated the influences of high temperature annealing treatment on the structure, mechanical, and electrical properties of the coating. We have prepared $\mathrm{AlCoCrFeNiTi}_{0.5}$ high-entropy alloy coatings by laser cladding. The purpose of this study is to investigate the effects of annealing on the microstructure and wear resistance of the $\mathrm{AlCoCrFeNiTi}{ }_{0.5}$ coatings.

\section{Experiment}

The alloy powder was mixed with $\mathrm{Al}, \mathrm{Co}, \mathrm{Cr}, \mathrm{Fe}, \mathrm{Ni}$, Ti alloy powders and the purities are above $99.9 \%$ for each one. The composition of $\mathrm{AlCoCrFeNiTi}_{0.5}$ alloy is shown in Table 1 . The substrate material for laser cladding is industrial pure iron.

The $\mathrm{AlCoCrFeNiTi}_{0.5}$ high entropy alloy coatings were prepared by laser cladding with HGL-6000 $\mathrm{CO}_{2}$ multifunctional numerically-controlled laser processing machine. The alloy powder for laser cladding was uniformly mixed by an agate mortar machine and preheated at $100{ }^{\circ} \mathrm{C}$ for $24 \mathrm{~h}$. The powder was preset on the base material and the thickness of the powder layer was $1.0 \mathrm{~mm}$. The laser power was $3500 \mathrm{~W}$, the scanning speed was $300 \mathrm{~mm} / \mathrm{min}$, and the spot diameter was $5 \mathrm{~mm}$. The cladding process was shielded with argon. The specimens were then annealed at $900{ }^{\circ} \mathrm{C}$ for $5 \mathrm{~h}$. The specimen structures were identified via $\mathrm{X}$-pert power X-ray diffraction (XRD) with $\mathrm{Cu}$ radiation operating at $40 \mathrm{kV} / 30$ $\mathrm{mA}$ and a scanning step of 0.065 and $2 \theta$ changed from $10^{\circ}$ to $70^{\circ}$. The XRD patterns were analyzed by High Score plus. The ground and polished specimen were etched in a solution of aqua regia for 5 to $20 \mathrm{~s}$. The microstructures were observed with a HITACHS-3400 N SEM. Vickers hardness was measured by a HITACHS-3400 N Vickers hardness tester with a loading force of $4.9 \mathrm{~N}$ and a loading time of $15 \mathrm{~s}$. The wear resistance was measured by a CSM-TRIBOMETER friction wear tester with normal load force of $13 \mathrm{~N}$ and reciprocating speed of $10 \mathrm{~cm} / \mathrm{s}$. The reciprocating linear distance was 24 $\mathrm{mm}$ and the friction pair was $\mathrm{SiN}$.

\section{Results and Discussion}

\subsection{Effect of annealing on crystal structure}

Fig. 1 shows the X-ray diffraction profiles of as-cast and as-annealed $\mathrm{AlCoCrFeNiTi}{ }_{0.5}$ high-entropy alloy coating. The results reveal a remarkable influence of annealing on the

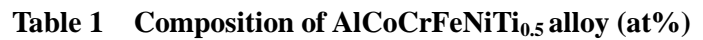

\begin{tabular}{ccccccc}
\hline Number & $\mathrm{Al}$ & $\mathrm{Co}$ & $\mathrm{Cr}$ & $\mathrm{Fe}$ & $\mathrm{Ni}$ & $\mathrm{Ti}$ \\
\hline $1 \# \& 2 \#$ & 9.76 & 21.32 & 18.81 & 20.21 & 21.24 & 8.66 \\
\hline
\end{tabular}

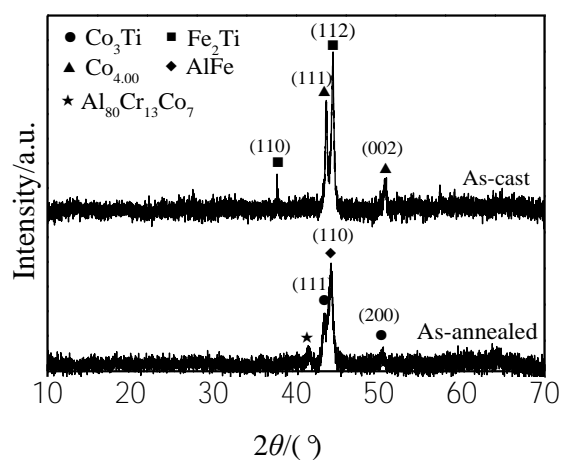

Fig.1 XRD patterns of as-cast and as-annealed $\mathrm{AlCoCrFeNiTi} \mathrm{C}_{0.5}$ high-entropy alloy coating

crystal structure evolution of the $\mathrm{AlCoCrFeNiTi}_{0.5}$ high entropy alloy. $\mathrm{Fe}_{2} \mathrm{Ti}$ and $\mathrm{Co}_{4.00}$ with simple fcc solid solution structure form in the as-cast specimen. After annealing at $900{ }^{\circ} \mathrm{C}$, AlFe with bcc structure and $\mathrm{Al}_{80} \mathrm{Cr}_{13} \mathrm{Co}_{7}$ and $\mathrm{Co}_{3} \mathrm{Ti}$ compounds appear. According to the formula of interplanar spacing, the lattice parameter of AlFe solid solution is 0.290 $\mathrm{nm}$, which is slightly less than that of bcc-Fe $(a=0.293 \mathrm{~nm})$. Meanwhile, some $\mathrm{Fe}$ atoms of bcc-Fe are replaced by $\mathrm{Al}$ atoms and formed AlFe phase. The similar phase was also observed in $\mathrm{L} 12-\mathrm{Co}_{3} \mathrm{Ti}$ intermetallic compounds ${ }^{[12]}$. Yuan Liu et $\mathrm{al}^{[13]}$ reported that compounds and ordered substitutional solid solutions formed when $\Delta H_{\text {mix }}<0$, while disordered solid solutions formed when $\Delta H_{\text {mix }} \approx 0$. The mixing enthalpies of $\mathrm{Al}-\mathrm{Fe}, \mathrm{Co}-\mathrm{Ti}$ and $\mathrm{Fe}-\mathrm{Ti}$ atomic pairs are less than 0 . According to $\Delta H_{\text {mix }}$ formula ${ }^{[14]}$, the mixing enthalpy $\Delta H_{\text {mix }}$ of $\mathrm{AlCoCrFeNiTi} i_{0.5}$ high-entropy alloy is $-17.92 \mathrm{~kJ} / \mathrm{mol}$, which is between $-40 \mathrm{~kJ} / \mathrm{mol}$ and $10 \mathrm{~kJ} / \mathrm{mol}$. Therefore, simple transpositional solid solutions are obtained in the investigated alloy system ${ }^{[15]}$. Both fcc and bcc transpositional solid solutions form in the annealed coatings, while only fcc solid solutions appear in the as-cast coatings.

\subsection{Effect of annealing on microstructure}

Fig. 2 shows the microstructures of as-cast and as-annealed $\mathrm{AlCoCrFeNiTi}_{0.5}$ alloy coatings in the center of the coatings. Fig.2a shows that the as-cast coatings consist of bulk dendrites and primary $\alpha$ phases, which is similar to the research results of Qunhua Tang et al ${ }^{[16]}$. This phenomenon indicates that dislocation, grain boundary and interface defects possibly exist within the as-cast alloys, which precipitate high thermodynamic free energy in unsteady state. The microstructure of the annealed specimen is fine and typical spinodal decomposition structures are formed in the interdendrite $^{[7,13,17]}$. EDS data of different regions of the coating are given in Table 2. Fig.2a shows that titanium segregates in the primary $\alpha$ phases because of rapid solidification during laser cladding and segregation character of titanium. The segregation of titanium has been eliminated in Fig.2b. $\mathrm{Fe}_{2} \mathrm{Ti}$ and $\mathrm{Co}_{4.00}$ solid solutions are formed in the dendrite and interdendrite, 


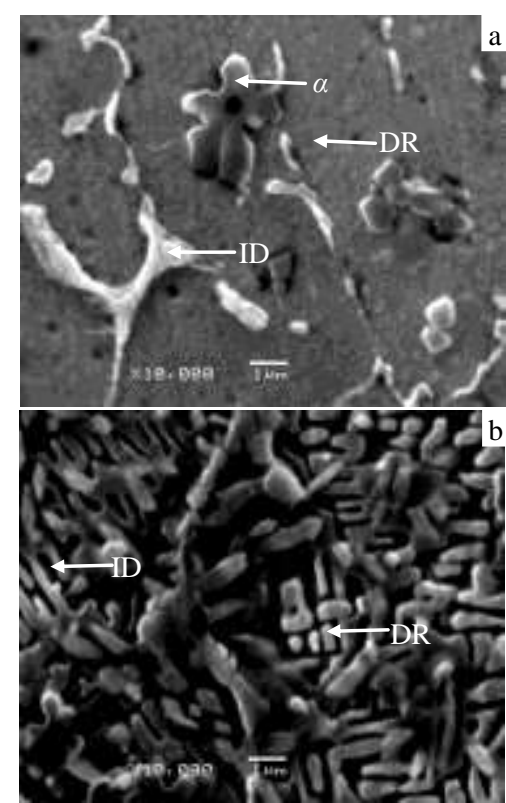

Fig.2 Microstructures of as-cast and as-annealed $\mathrm{AlCoCrFeNiTi}_{0.5}$ alloy coating

Table 2 EDS data of different regions of the coating in Fig.2 (at \%)

\begin{tabular}{cccccccc}
\hline Condition & Region & $\mathrm{Al}$ & $\mathrm{Co}$ & $\mathrm{Cr}$ & $\mathrm{Fe}$ & $\mathrm{Ni}$ & $\mathrm{Ti}$ \\
\hline \multirow{4}{*}{ As-cast } & $\mathrm{DR}$ & 12.11 & 13.49 & 13.79 & 42.48 & 13.84 & 4.31 \\
& $\mathrm{ID}$ & 9.77 & 14.23 & 27.47 & 34.55 & 11.55 & 2.44 \\
& $\alpha$ & 24.75 & 5.57 & 7.96 & 11.68 & 5.49 & 44.55 \\
\hline \multirow{2}{*}{ As-annealed } & $\mathrm{DR}$ & 17.01 & 13.00 & 17.96 & 36.88 & 14.24 & 0.91 \\
& $\mathrm{ID}$ & 23.90 & 13.41 & 12.81 & 28.09 & 20.68 & 1.12 \\
\hline
\end{tabular}

respectively, in Fig.2a. Grain boundary is devoured and typically spinodal decomposition microstructures form in the annealed coating. The formation of the spinodal decomposition microstructures is related to stress field formed by grain boundary, dislocation, vacancy etc in the as-cast sample. The contents of $\mathrm{Al}$ and $\mathrm{Fe}$ are rich in dendrites. The elasticity modulus of $\mathrm{Al}$ and $\mathrm{Fe}$ are different in spinodal decomposition microstructures, the whole system forms nonuniform elasticity modulus and AlFe will separate out in anisotropic state. Similar results were reported by Ziqing Weng et $\mathrm{al}^{[18]}$ in their study on annealed FeCrNiCoMn high-entropy alloy coating prepared by laser cladding.

\subsection{Effect of annealing on Vickers hardness}

Fig. 3 shows the hardness of as-cast and as-annealed $\mathrm{AlCoCrFeNiTi}_{0.5}$ coating. The average Vickers hardness of the as-annealed specimens is $9890 \mathrm{MPa}$, which is increased by $73.5 \%$ compared with that of the as-cast specimen. Hardness increasing is mainly because of solute strengthening and precipitated strengthening. Firstly, complex phase $\mathrm{Al}_{80} \mathrm{Cr}_{13} \mathrm{Co}_{7}$ and AlFe solid solution with bcc structure form in the annealed alloy, which can enhance hardness by increasing lattice distortion and preventing slippage. Similar results were

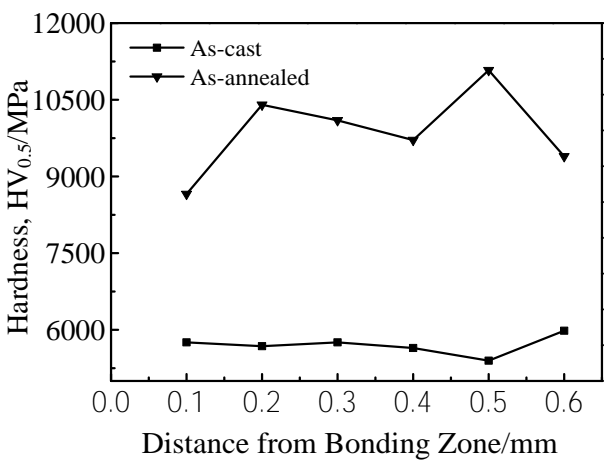

Fig.3 Hardness of $\mathrm{AlCoCrFeNiTi} i_{0.5}$ alloy coating

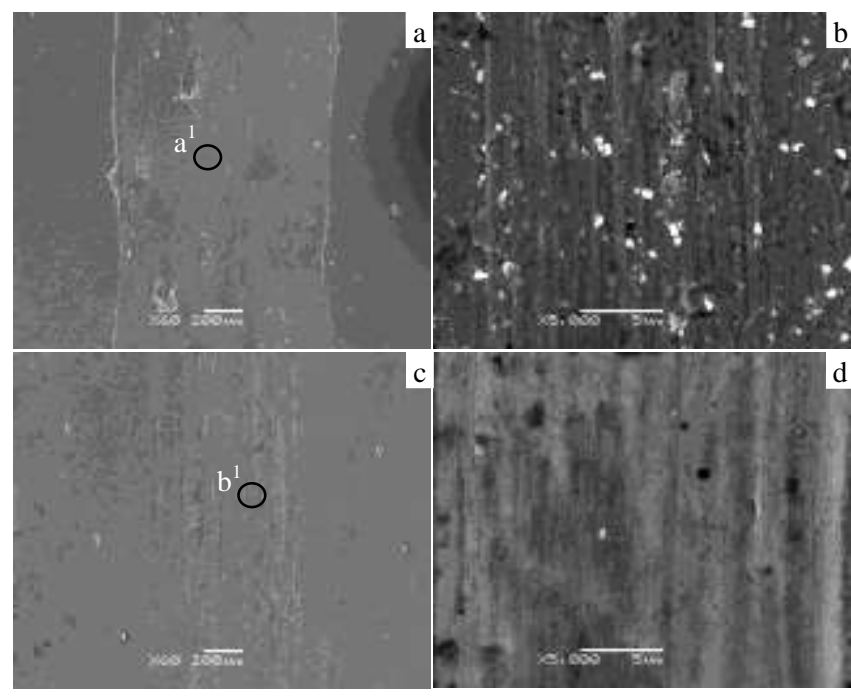

Fig.4 SEM micrographs of polishing scratch foras-cast $(a, b)$ and as-annealed (c, d)

given by Ziqing Weng et al ${ }^{[18]}$. Secondly, fine and uniform spinodal decomposition microstructures lead to much higher hardness in as-annealed coatings.

\subsection{Effect of annealing on wear resistance}

Fig.4 shows SEM micrographs of grinding crack. Fig.4a and $4 \mathrm{~b}$ show that the wear width in the as-cast sample is twice the size of that in as-annealed sample. Meanwhile, the wear scar of the annealed sample is relatively smooth and shiny, which indicates that the fine spinodal decomposition microstructures form a compact protective film on the surface. The mass loss of the as-annealed sample is $0.4 \mathrm{mg}$, which is decreased by $92.5 \%$ compared with that of the as-cast sample. Solid solution with bcc structure and typical fine spinodal decomposition microstructures are formed in the as-annealed coating, which increases wear resistance because of solute strengthening and precipitated strengthening.

\section{Conclusions}

1) $\mathrm{AlCoCrFeNiTi} i_{0.5}$ high entropy alloy coatings are prepared 
by laser cladding and annealed at $900{ }^{\circ} \mathrm{C}$ for $5 \mathrm{~h}$. The phases of the annealed samples are $\mathrm{Co}_{3} \mathrm{Ti}$ and solid solutions with bcc structure, which are superior to those in as-cast coating.

2) Fine and uniform components spinodal decomposition microstructures are formed in the annealed coatings, while the microstructures of the as-cast samples are coarse dendrites and primary $\alpha$ phases. The compositional variation is decreased and the segregation of titanium disappears in the as-annealed sample.

3) The average Vickers hardness of the annealed samples is $9890 \mathrm{MPa}$, which is increased by $73.5 \%$ compared with that of the as-cast samples. The mass loss is decreased by $92.5 \%$ and the wear width is decreased by $50 \%$ for the annealed samples.

\section{References}

1 Yeh J W, Chen S K, Lin S J et al. Advanced Engineering Materials[J], 2004, 6: 299

2 Zhou Y J, Zhang Y, Wang X F et al. Rare Metals[J], 2008, 27(6): 627

3 Huang Biao, Zhang Chong, Cheng Hu et al. China Surface Engineering [J], 2014, 27(6): 82

4 Lu Y P, Dong Y, Guo S et al. Scientific Reports[J], 2014, 4: 6200

5 Dong Y, Zhou K Y, Lu Y P et al. Materials and Design[J], 2014, 57: 67

6 Dong Y, Lu Y P, Kong J R et al. Journal of Alloys and
Compounds[J], 2013, 573: 96

7 Wang W R, Wang W L, Wang S C et al. Intermetallics[J], 2012, 26: 44

8 Luo Xiaoyan, Liu Guizhong, Gao Yuan. Materials for Mechanical Engineering [J], 2011, 35(4): 87

9 Li Wei, Liu Guizhong, Luo Xiaoyan et al. Materials for Mechanical Engineering[J], 2010, 34(2): 43

10 Wang Y F, Ma S G, Chen X H et al. Acta Metallurgica Sinica[J], 2013, 26(3): 277

11 Zhang H, Pan Y, He Y Z. Journal of Thermal Spray Technology [J], 2011, 20(5): 1049

12 Leng Wenxiu, Tian Wenhuai. Journal of University of Science and Technology Beijing [J], 2009, 31(2): 193

13 Liu Yuan, Chen Min, Li Yanxiang et al. Rare Metal Materials and Engineering[J], 2009, 38(9): 1602 (in Chinese)

14 Xia M X, Zhang S G, Li J G. Applied Physics Letters[J], 2006, 88: 261913-1

15 Ren M X, Li B S, Fu H Z. Transactions of Nonferrous Metals Society of China[J], 2013(23): 991

16 Tang Qunhua, Cai Jianbin, Wu Guifen et al. Foundry[J], 2011, 60(1): 24

17 Zhao R D, Zhu J C, Lai Z H et al. Journal Shanghai Jiaotong University (Science) [J], 2012, 17(4): 461

18 Weng Ziqing, Dong Gang, Zhang Qunli et al. Chinese Journal of Lasers[J], 2014, 41(3): 0303002-1

\title{
退火对激光熔覆 $\mathrm{AlCoCrFeNiTi} \mathbf{0}_{0.5}$ 高熵合金涂层组织和耐磨性的影响
}

\author{
沙明红, 张 丽, 张峻巍, 李 娜, 李泰增, 王 宁 \\ (辽宁科技大学, 辽宁 鞍山 114051)
}

\begin{abstract}
摘 要：对激光熔覆 $\mathrm{AlCoCrFeNiTi}$. 高熵合金涂层进行 $900{ }^{\circ} \mathrm{C}$ 退火, 保温 $5 \mathrm{~h}$ 处理。主要对退火前后样品的微观结构和耐磨性进行研究。 XRD结果表明, 退火后的 $\mathrm{AlCoCrFeNiTi}_{0.5}$ 高熵合金涂层, 其相组成有 $\mathrm{Co}_{3} \mathrm{Ti}_{1}$ 和bcc结构的 $\mathrm{AlFe}$ 固溶相, 出现典型的成分均匀的网状调幅分 解组织; 退火后的平均显微硬度达到 $9890 \mathrm{MPa}$, 比退火前提高了 $73.5 \%$; 耐磨性测试结果显示, 退火后磨损量比退火前降低了92.5\%, 磨损宽度是退火前的 $50 \%$ 。
\end{abstract}

关键词：高熵合金；退火；而磨性；激光熔覆

作者简介: 沙明红, 女, 1976 年生, 副教授, 辽宁科技大学材料与冶金学院, 辽宁 鞍山 114051, E-mail: hongsmh_116@163.com 